\title{
Local-Scale Environmental Filtering Shape Plant Taxonomic and Phylogenetic Diversity in the Isolated Amazonian Tepui (Tepequém Table Mountain)
}

\section{Prímula Campos ( $\nabla$ primula.vc@gmail.com )}

Universidade Federal de Viçosa Centro de Ciências Biológicas e da Saúde: Universidade Federal de Vicosa Centro de Ciencias Biologicas e da Saude

\section{Carlos Ernesto Schaefer}

Universidade Federal de Vicosa

\section{Vanessa Pontara}

UEMS: Universidade Estadual do Mato Grosso do Sul

\section{Márcio Xavier}

Universidade Federal de Minas Gerais

José Frutuoso Vale Júnior

Universidade Federal de Roraima

\section{Guilherme Corrêa}

Universidade Federal de Uberlandia

\section{Pedro Villa}

$$
\text { Universidade Federal de Vicosa }
$$

\section{Research Article}

Keywords: mountainous ecosystems, plant-soil relationship, phylogenetic composition, Rupestrian Grassland Complex, tepuis flora

Posted Date: April 16th, 2021

DOl: https://doi.org/10.21203/rs.3.rs-385044/v1

License: (1) This work is licensed under a Creative Commons Attribution 4.0 International License. Read Full License

Version of Record: A version of this preprint was published at Evolutionary Ecology on November 29th, 2021. See the published version at https://doi.org/10.1007/s10682-021-10141-w. 


\section{Abstract}

Understanding how environmental drivers induce changes in plant composition and diversity across evolutionary time can provide important insights into the mechanisms of community assembly. We evaluated how taxonomic and phylogenetic diversity and structure of plant communities change along a local-scale edaphic and topographic gradient in the Tepequém table mountain, Brazilian Amazon. We selected three phytophysiognomies along the altitudinal gradient: Open Rupestrian Grassland, Shrubby Rupestrian Grassland, and Forest. We compared community composition and taxonomic and phylogenetic diversity between phytophysiognomies, and we tested regression linear effect models to investigate the effect of altitude and soil properties on taxonomic and phylogenetic diversity. The highest species richness and phylogenetic diversity were found at lower elevation for Forest. Mean pairwise phylogenetic distance, mean nearest taxon phylogenetic distance, and all standardised phylogenetic metrics were significantly lower in Shrubby Rupestrian Grassland. This phytophysiognomy showed phylogenetic clustering. Forest showed a cluster pattern when only terminal nodes are considered and random dispersion to deep phylogenetic nodes. Open Rupestrian Grassland also showed random phylogenetic structure. The regression analyses showed that species richness and different phylogenetic diversity metrics were explained by altitude and soil properties. However, standardised metrics were not explained by these environmental variables. Comprehensive studies including the role of environmental drivers in plant evolutionary history along the altitudinal gradient are necessary for explaining community assembly patterns and provide additional information for conservation planning.

\section{Introduction}

Mountain ecosystems have been recognised as a remarkable ecological scenario to evaluate the effect of environmental drivers on plant community diversity and structure (Qian et al. 2014; Liu et al. 2019a). These ecosystems are of Earth's most biodiverse region (Körner et al. 2017), due to the higher variability of abiotic-related factors (e.g. climate and soil properties) along local environmental gradients, such as elevation (Körner et al. 2017; Pashirzad et al. 2018). Thus, elevation can induce changes in temperature, precipitation, and edaphic conditions (Benites et al. 2003; Körner et al. 2017), which influence the taxonomic diversity, composition, structure (Mota et al. 2016; Campos et al. 2018; Cordeiro and Neri 2019), and evolutionary history of plant communities (Chu and Lee 2018; Pontara et al. 2018; Liu et al. 2019a; Rezende et al. 2019; Campos et al. 2021). However, most studies on altitudinal gradients in tropical mountains have focused on the effects of abiotic variables on floristic composition and species richness (e.g. Neri et al. 2017; Campos et al. 2018; Mota et al. 2018). Thus, knowledge of their effects on communities' evolutionary history is still limited, mainly in ancient climate buffered and nutrient-poor Neotropical mountains.

The plant communities' assembly is associated with stochastic processes based on neutral theory to explain different ecological processes, such as dispersal limitation, speciation, and extinction (Hubbell 2001; Liu et al. 2019a) and niche-related deterministic processes, such as environmental filtering and limiting similarity (Webb et al. 2002; Cadotte et al. 2011). In this context, an approach based on 
phylogenetic diversity of plant communities can provide insights to explain ecological processes that shape the assemblages along environmental gradients at local and regional scales (Webb 2000; Liu et al. $2019 a, b)$. Thus, the niche-related deterministic processes postulate that plant species interactions with their environment are mediated by different functional traits, and more related species have more similar functional traits and niche resources explored (Webb 2000; Liu et al. 2019a). Thus, if functional traits are conserved within evolutionary lineages, communities shaped by environmental filters show a more clustered phylogenetic structure (Cavender-Bares et al. 2009; Wiens et al. 2010). Conversely, overdispersed patterns suggest that density-dependent processes (e.g. competitive exclusion) are dominant and determine the phylogenetic structure of communities (Webb et al. 2002; Cavender-Bares et al. 2009). However, biotic interactions (e.g. competition) can also lead to clustered phylogenetic structure when the exclusion occurs among distantly related organisms (Mayfield and Levine 2010). Furthermore, the local ecological community can show a random phylogenetic pattern when various niche-based processes operating simultaneously in species selection or neutral factors are more important (Webb 2000; Sobral and Cianciaruso 2012).

Previous studies in mountains documented the environmental filtering effect by harsh climatic and edaphic conditions at higher elevations and competitive exclusion at lower elevations driving the increased and decreased phylogenetic relatedness, respectively (Li et al. 2014; Qian et al. 2014; Manish and Pandit 2018). Among Neotropical mountain ecosystems, the isolated table mountains (called tepuis), Guayana Shield region in the northern South America (Huber 1987; Safont et al. 2014), are considered a natural laboratory to evaluate key ecological and evolutionary processes of the biota worldwide (Rull et al. 2016; 2019). The tepuis are modelled on Precambrian quartzites/sandstones (Huber 1987; Rull 2007; Safont et al. 2014), with elevation ranging from approximately 1,000 to $3,000 \mathrm{~m}$ (Huber 1995). They are considered virtually pristine environments, with high host levels of biodiversity and endemism (Rull 2007; Safont et al. 2016). Similarly to the rupestrian grassland complex, in eastern Brazilian mountains (Schaefer et al. 2016), tepuis are characterised by distinct physiognomies, including forests, shrublands, high-mountain meadows, grasslands, and pioneer vegetation (Huber 1995). In addition, both rupestrian ecosystems share similar environmental conditions, such as high mountain climate, extensive areas of rocky outcrops, and soil that is generally poor, acidic, shallow, and water-deficient (Schaefer et al. 2016).

In South American highland rupestrian ecosystems, small differences in altimetric and soil conditions are important drivers of plant community assembly, influencing the taxonomic diversity patterns (Neri et al. 2017; Campos et al. 2018; Mota et al. 2018). In mountain ecosystems, studies have revealed that different abiotic factors (e.g. climate and soil) at fine-scale altitudinal gradients play significant roles in plant phylogenetic diversity (Li et al. 2014; Qian et al. 2014; Chun and Lee 2018). However, no detailed study has evaluated these patterns along the altitudinal gradient in tepuis. Attempts to address this knowledge gap could be of importance for understanding the mechanisms and process that shape the plant communities of tepuis and to establish strategies and actions for biodiversity conservation.

In this context, we aimed to evaluate how taxonomic and phylogenetic patterns of plant communities change along a local-scale edaphic and topographic gradient in the Tepequém table mountain, Brazilian 
Amazon. Thus, we established the following research questions: i) How do plant community composition, structure, and diversity (taxonomic and phylogenetic) change along a local-scale edaphic and topographic gradient? ii) What is the effect of different environmental predictors (altitude and edaphic-related factors) on taxonomic and phylogenetic community structure and diversity? Our hypothesis was that the local-scale environmental filtering (altitude and edaphic-related factors) is the main process that shapes plant community assemblages in Tepequém table mountain. Thus, we predict that harsh edaphic conditions and altitude impose a strong environmental filter to species richness, composition, and phylogenetic diversity, but lead a similar pattern of community phylogenetic structure along phytophysiognomies. Therefore, we expected that these communities in edaphic soil conditions would show more phylogenetic clustering because of the strong effect of environmental filtering.

\section{Materials And Methods}

\section{Study area}

The study was conducted on Tepequém table mountain located in Roraima state, northwestern Brazil $\left(03^{\circ} 45^{\prime} 54,6^{\prime \prime} \mathrm{N}\right.$ and $61^{\circ} 41^{\prime} 17,5^{\prime \prime} \mathrm{W}$; Fig. 1). This tepui reaches approximately $1100 \mathrm{~m}$ of altitude (Beserra Neta et al. 2015; Nóbrega et al. 2016), and comprises $70 \mathrm{~km}^{2}$ in total area (Reis and Carvalho 1996). According to Köppen's classification, the region has a humid tropical climate (Am), with a mean annual temperature and precipitation are $28^{\circ} \mathrm{C}$ and $1600 \mathrm{~mm}$, respectively (Barbosa and Miranda 2004).

The regional geomorphology is characterised mainly by erosive scarps, steep slopes, valleys and residual mountains (Rodríguez-Zorro et al. 2017). Geologically this tepui represents residuals of ancient erosional landsurfaces, supported by thick tabular sandstones of the Proterozoic Roraima Supergroup (AlmeidaFilho and Shimabukuro 2002). The top stratigraphic unit corresponds to the Tepequém Formation composed mainly of sandstone and conglomerates, lying over acid to intermediate Early Proterozoic volcanites of the Surumu Group (Almeida-Filho and Shimabukuro 2002).

The vegetation of Tepequém table mountain is characterised predominantly by Ombrophilous Dense Forest extending through the slopes and scarps (Nascimento et al. 2012) associated with Haplic Cambisol and Yellow Red Latosol (Beserra Neta et al. 2015). Moreover, this table mountain has a typical Rupestrian Grassland Complex distributed mainly between 650 and $1100 \mathrm{~m}$ a.s.l., influenced by savannic formation, with sclerophyllous vegetation ranging from grassy to the shrubby formation, usually on Quartzarenic and Litholic Neosols (Silva 1997).

\section{Data collection}

The sampling was performed at three main Rupestrian Grassland Complex phytophysiognomies along the altitudinal gradient: i) Open Rupestrian Grassland (ORG) in plots ranging from 923 to $1100 \mathrm{~m}$ altitude; ii) Shrubby Rupestrian Grassland (SRG), from 690 to 855 m; and iii) Forest (FOR), from 450 to $600 \mathrm{~m}$. In each of the three different phytophysiognomies were used plot sizes that were adequate for each predominant life form. In the herbaceous vegetation from ORG, we randomly distributed 80 plots $(1 \times 1$ 
$\mathrm{m})$. Plant community structures were evaluated by the cover-abundance scale proposed by BraunBlanquet (1979). To woody vegetation, 60 plots $(20 \times 20 \mathrm{~m})$ were arbitrarily established, i.e. 30 plots along the SRG and 30 plots along the FOR. Each plot in the same phytophysiognomies was at least $40 \mathrm{~m}$ apart from each other. In the SRG, all individuals presenting circumference at soil height (CSH) $\geq 3 \mathrm{~cm}$ were sampled, while in the FOR sampling was performed of all individuals presenting circumference at $1.30 \mathrm{~m}$ from the soil $(\mathrm{CBH}) \geq 15 \mathrm{~cm}$ (Moro and Martins 2011). Number of individuals for each species were registered in each plot.

The fertile botanical samples were deposited in the Herbarium VIC at the Universidade Federal de Viçosa (Minas Gerais, Brazil). Identifications were made by consulting specialists and the literature. Taxonomic classification followed APG IV (Angiosperm Phylogeny Group 2016). Overall, 7325 individuals were sampled, among 108 angiosperm species, 88 genera, and 24 families (Supplementary Material; Fig. S1).

The physicochemical properties of the soil were sampled as abiotic variables along an altitudinal gradient of Tepequém table mountain. A composite sample of three topsoil subsamples (0-10 cm depth) was collected for each plot. Samples were air-dried and sifted through a $2 \mathrm{~mm}$ mesh sieve. Analyses were conducted at the Laboratory of Soil Analysis, Universidade Federal de Viçosa, following international standards (Embrapa 2017). The analyses active acidity $(\mathrm{pH})$ in water; exchangeable potassium $\left(\mathrm{K}^{+}\right)$; sodium $\left(\mathrm{Na}^{+}\right)$; calcium $\left(\mathrm{Ca}^{2+}\right)$; magnesium $\left(\mathrm{Mg}^{2+}\right)$ and aluminum $\left(\mathrm{Al}^{3+}\right)$; potential acidity $(\mathrm{H}+\mathrm{Al})$; available phosphorus $(P)$; remaining phosphorus (P-rem); sum of bases $(B S)$; base saturation $(V)$; aluminum saturation $(\mathrm{m})$; total cation exchange capacity (CEC); micronutrients ( $\mathrm{Zn}, \mathrm{Fe}, \mathrm{Mn}$ and $\mathrm{Cu}$ ); organic matter content (OM); and included: granulometry (clay, silt, coarse and fine sand contents).

\section{Data analyses}

\section{Taxonomic and phylogenetic composition}

All analyses were carried out using R software version 3.6.2 (R Core Team 2020). We performed a nonmetric multidimensional scaling (NMDS) multivariate analysis based on Bray-Curtis dissimilarity (based in abundance data) to compare species composition between phytophysiognomies (Bray and Curtis 1957). After, a permutational multivariate analysis of variance (PERMANOVA, 9999 permutations) was used to determine differences in species composition between phytophysiognomies using the adonis routine available within the "vegan" package (Oksanen et al. 2018).

We performed evolutionary principal component analysis based on Hellinger distance (evoPCAHellinger) to analyze for differences in phylogenetic composition across phytophysiognomies (Pavoine 2018). This approach on balances the influence of deep and shallow nodes on the ordination analysis represents one of the more powerful methods to study phylogenetic patterns across underlying environmental variation (Pavoine 2016). We implemented this approach using the evoPCAHellinger function in the "adiv" package (Pavoine 2018).

\section{Taxonomic and phylogenetic diversity and structure}


We determined the species richness as the sum of all species found in all plots in each phytophysiognomy. We generated a phylogenetic tree including a pooling of all species using a mega-tree approach in the V.PhyloMaker package (Jin and Qian 2019). This mega-tree contains 74,533 vascular plant species based on the APG IV phylogenetic system of angiosperm classification, and includes all plant families of the world (Jin and Qian 2019). We used the phylo.makerfunction makes phylogenetic hypotheses under the scenario 3 which consist in the tips of a new genus or specie not included in the mega-tree were bound to the half-point of the family or genus branch, representing the branch between the family and genus root node and the basal node (Jin and Qian 2019).

We calculated metrics that evaluate the evolutionary history for each phytophysiognomies; such as phylogenetic diversity (PD, in millions of years, myrs), correspond the sum of the branch lengths of a phylogenetic tree connecting all species in a community (Faith 1992); mean pairwise phylogenetic distance (MPD), is the average phylogenetic distance between all combinations of pairs of individuals (including conspecifics) in a community; and mean nearest taxon distance (MNTD), correspond the average phylogenetic distance between an individual and its most closely related (non-conspecific) individual (Webb 2000; Webb et al. 2008). To remove the influence of species richness, we calculated their equivalents standardized based on a null model (ses.PD, ses.MPD, ses.MNTD) (Swenson 2014). Negative ses.MPD and ses.MNTD values indicate phylogenetic clustering (species are distributed within clades with relatively recent common ancestors, or are more closely related than expected by chance), while positive values indicate phylogenetic overdispersion (species more distantly related to each other than expected by chance) (Webb et al. 2002). For the standardised effect size calculations, our tree was compared with 10,000 null model randomizations using the algorithm 'phylogeny pool'. We calculated these metrics using "picante" package (Kembel et al. 2015) in the R software version 3.6.2 (R Development Core Team 2020).

\section{Statistical analyses}

All statistical analyses were carried out using R software version 3.6.2 (R Development Core Team 2020). Data normality and distribution were verified by the Shapiro-Wilk test for normality and Q-Q graphs (Crawley 2013). Differences in the species richness and phylogenetic metrics across the phytophysiognomies were analyzed by using one-way analysis of variance (ANOVA; for normally distributed data) followed by a post hoc Tukey's test $(p<0.05)$. Post-hoc Tukey HSD tests were applied to outline significance levels of phylogenetic structure differences among single phytophysiognomy.

We used a Kruskal-Wallis test to compare soil attributes (Supplementary Material, Table A1) followed by a posteriori Dunn's test (Dinno 2017). All analyses were calculated using the "stats" and "dunn.test" packages (Dinno 2017). Soil variables were summarized by using principal component analysis (PCA), proceeded by standardisation by logarithmic transformation, in order to equalise their contributions on the axis (Supplementary Material, Fig. S2). Water $\mathrm{pH}\left(\mathrm{pH}_{-} \mathrm{H}_{2} \mathrm{O}\right)$ values were not transformed because they are already expressed on a logarithmic scale. We also calculated Pearson correlations among soil properties (Supplementary Material, Fig. S3). The PCA was performed using the "FactoMineR" package 
(Husson et al. 2017). To reduce any strong correlations among soil attributes the first and second axis was considered to be a proxy for soil fertility and texture across analyses (Villa et al. 2018; Schmitz et al. 2020). Thus, we defined the first and second PCA axis for soil fertility (PCA1f; PCA2f) and texture (PCA1t; PCA2t) variables.

Finally, we used linear regression models to investigate the main effects of different predictor variables on plant taxonomic and phylogenetic diversity and structure. Species richness and phylogenetic metrics were used as the dependent variables. Altitude, soil fertility (PCA1f and PCA2f), and soil texture (PCA1t and PCA2t) were used as the independent variables in the models. The linear regression models were performed using the "car" package (Fox et al. 2014).

\section{Results}

\section{Taxonomic and phylogenetic composition}

The NMDS showed that species composition varied considerably among phytophysiognomies along the altitudinal gradient, mainly among FOR with SRG and ORG (Fig. 2a). In the evolutionary composition ordination a contrasting phylogenetic composition pattern was observed between phytophysiognomies (Fig. 2b). Three groups were clearly separated according to the first two evoPCa axes, which together explained $48.6 \%$ of the total data variation. The first axis $\left(\mathrm{PC}_{1}, 27 \%\right)$ separated plots from FOR with positive values from the rest of the plots in ORG and SRG with negative values. This axis is strongly and negatively correlated with lineages related to the Poales clade, especially the families Poaceae, Cyperaceae, and Xyridaceae, with highest number of species in ORG (Fig. 2c). The second axis ( $\mathrm{PC}_{2}$, $21.6 \%$ ) separated most of the plots from FOR and ORG, with negative values, of the SRG plots with positive values. The second axis is strongly and negatively correlated with the Pandanales (family Velloziaceae), Asparagales (family Orchidaceae) and Poales clades, with a high number of species in ORG; and strongly and positively correlated with Nitrogen fixers to COM, mainly Fabales (Fabaceae) and Malpighiales clades, with a higher number of species in SRG and FOR (Fig. 2C). The second axis also correlated with Magnoliales (family Annonaceae) and Laurales (Lauraceae), both with higher number of species in FOR.

\section{Taxonomic and phylogenetic diversity and structure}

We observed differences in species richness among phytophysiognomies (ANOVA, $F_{11,43}, p<0.001$ ). FOR had the highest species richness (55), followed by SRG (32), and ORG (29). Phylogenetic diversity (PD, in myrs) showed similar patterns as we found for species richness, once that metrics both are highly correlated (Supplementary Material, Fig. S4). The highest value was found for FOR (1716.465 Ma), while the lowest value was found for ORG (366.047 Ma) (Fig. 3a). The SRG showed intermediate values (848.602 Ma). Mean pairwise distance (MPD) was higher in ORG and FOR, while mean nearest taxon distance (MNTD) was higher only in ORG (Fig. 3c; 3e). The same pattern of phylogenetic diversity was found for the standardised metrics, where the highest and close to zero ses.PD and ses.MPD values were 
found in ORG and FOR (Fig. 3b; 3d). Only, ORG showed the highest value for ses.MNTD (Fig. 3f). For ses.MNTD, SRG was not significantly different from FOR. Both phytophysiognomies showed clustering pattern. SRG showed strong negative values for all standardized metrics; ses.MPD and ses.MNTD indicated phylogenetic clustering for deep and shallow nodes, respectively.

\section{Effects of altitude, soil fertility and texture on species richness and phylogenetic metrics}

The regression analyses showed that species richness and different phylogenetic metrics were explained mainly by the altitude, soil texture and fertility properties (Fig. 4; Supplementary Material, Table A2). Species richness and PD showed similar patterns due the high correlation between them (Supplementary Material, Fig. S4). PD was negatively related to altitude $\left(r^{2}=0.81 ; p<0.001\right)$, PCA1 $f\left(r^{2}=0.19 ; p<0.001\right)$, and PCA2t $\left(r^{2}=0.16 ; p<0.001\right)$. MPD negatively related only with altitude $\left(r^{2}=0.07 ; p<0.001\right)$. MNTD showed contrary pattern to species richness and PD, with positive relation to altitude, PCA1 $\mathrm{f}$, and PCA2t.

\section{Discussion}

In this study, we revealed significant differences in plant community composition, structure, and diversity (taxonomic and phylogenetic) along a local-scale edaphic and altitudinal gradient. Our results showed that significant effects of altitude and edaphic-related factors on species richness and communities phylogenetic diversity highlight the importance of fine-scale environmental heterogeneity for the maintenance of high biodiversity levels in tepuis (Vegas-Vilarrúbia et al. 2012; Safont et al. 2014; 2016). We predicted that harsh edaphic conditions and altitude would impose a strong environmental filter on vegetation, resulting in phylogenetic clustering. However, we presume that other environmental filters, stochastic factors, and biotic interactions also may be responsible for the community assembly of Tepequém table mountain, a tepui with high ecological importance for the Amazon region.

The community composition changes considerably among phytophysiognomies along the altitudinal gradient. According to Schaefer et al. (2016), soil depth, drainage, and landscape stability and evolution have a key role in variations of rupestrian grassland complex phytophysiognomies. Physical environment influences not only the species distributions but also community composition (Nunes et al. 2015; Fernandes 2016). ORG was strongly associated with members of the following families: Velloziaceae (Pandales); Orchidaceae (Asparagales); and Poaceae, Cyperaceae, and Xyridaceae (Poales). In open physiognomies of rupestrian ecosystems, these families are among the most important by dominating the herbaceous monocot stratum (Porembski 2007; Le Stradic 2015; Silveira et al. 2016; Silva et al. 2019). Its high representativeness is due to the ability of the species to colonise harsh environments under severe stress conditions, with a broad array of adaptations (Porembski 2007). Similarly, Fabaceae, Annonaceae, and Lauraceae, with a high representativeness of lineages in SRG and FOR, are essential in the woody strata structuration of rupestrian ecosystems. For example, taxa of the Fabaceae family are important for the dynamics of poor-nutrient ecosystems due to morphological adaptations, such as nodules in the roots (Oliveira et al. 2012). 
Variation in environmental conditions across phytophysiognomies along the altitudinal gradient such as lower temperatures as well as shallow soils with low water-holding capacity also seems to be the main factor leading to variation of species richness, PD, MPD, and MNTD in plant communities in the Tepequém table mountain. Harsh climatic and edaphic conditions in high altitudes represent a filter to plant species' establishment and growth (Zhang et al. 2014; Cordeiro and Neri 2018), and consequently influence the richness and evolutionary history of communities. Between ORG and FOR, there is an altitudinal difference of $650 \mathrm{~m}$, and a corresponding decrease of ca. $3.90^{\circ} \mathrm{C}$ in temperature. Such a correlation has been observed in other tepuis, which show an adiabatic temperature decrease of $0.60^{\circ} \mathrm{C} / 100 \mathrm{~m}$ elevation (Huber 1995; Vilarrúbia et al. 2012), and in several tropical mountain ecosystems, which show values ranging between $0.50^{\circ} \mathrm{C}$ and $0.70^{\circ} \mathrm{C}$ at each $100 \mathrm{~m}$ (Safford 1999; McCain and Grytnes 2010). Along the altitudinal gradient, other harsh climate conditions related to high altitudes, such as high solar radiation, high evapotranspiration, and wind exposure may prevent the establishment of a large number of species (Fernandes et al. 2016; Zhang et al. 2014) and can account for the results obtained.

The ses.MPD of the ORG and FOR was close to zero, suggesting a random phylogenetic structure when deep (old) phylogenetic nodes are considered. ORG showed a similar pattern when only shallow (recent; ses.MNTD) nodes are considered. This pattern may suggest that neutral processes, such as dispersal limitation and random speciation (Hubbel, 2001), can shape local communities (e.g. Chun and Lee 2018; Liu et al. 2019a) or that environmental filtering and competitive exclusion act simultaneously in different phytophysiognomies in the Tepequém table mountain (Mayfield and Levine 2010; Liu et al. 2019a). Conversely, ses.MNTD in FOR resulted in a clustered pattern. Our findings indicate that although the forest phytophysiognomy is characterised by a phylogenetically random tree community for deep phylogenetic nodes (i.e. order and family level), this same community has species more closely related than expected by chance when only terminal nodes are analysed (i.e. intra-familial and/or intra-generic level).

The phylogenetic clustering pattern found in SRG may be related to the higher competitive abilities of some species in this phytophysiognomy. Clustered phylogenetic patterns can also result from densitydependent biotic interactions (i.e. competition), once closely related species tend to have similar competitive abilities (Mayfield and Levine 2010). This occurs when competitive exclusion takes place among distantly related taxa (Mayfield and Levine 2010; Goberna et al. 2014). For example, SRG showed a high density of Byrsonima crassifolia (L.) Kunth and Byrsonima crispa A. Juss. individuals. Both species concentrate approximately $53 \%$ of the total individual numbers for this phytophysiognomy. The genus is known for the high production of secondary metabolites, mainly in leaves, with high phytotoxic and cytotoxic activity (Amâncio et al. 2019). However, we highlight that phylogenetic patterns discussed here should be improved by exact measurements of ecological traits for each species in the communities, followed by specific testing for the presence of a strong phylogenetic signal in relation to these traits (Cavender-Bares et al. 2009). 
In addition, we cannot discard that further explanations are possible for clustering pattern in the shrubby community assembly (e.g. abiotic constraints; Cavender-Bares et al. 2009). Multiple drivers may generate similar phylogenetic patterns (Cadotte et al. 2017), with environmental filters being the most common in rupestrian habitats (Miazaki et al. 2015; Zappi et al. 2017, 2019). Given the tendency of predominance towards niche conservatism in the rupestrian grasslands (Zappi et al. 2017), we expected that environmental filters related to local-scale edaphic and altitudinal gradient would influence phylogenetic clustering in the phytophysiognomies in the Tepequém table mountain. However, we observed that the standardised metrics were not explained by the variability of soil texture, fertility properties, or altitude. However, we suggest that other abiotic filters not evaluated in this study area could shape the phytophysiognomies in the phylogenetic clustering pattern, such as the temperature and soil water status (Ferrari et al. 2016) and rockiness (Pontara et al. 2018).

Nevertheless, differences in the species richness, PD, and MNTD among phytophysiognomies are related to local-scale edaphic gradients. In rupestrian ecosystems, the soil is an important driver at the local scale on plants' taxonomic (Nunes et al. 2015; Mota et al. 2018) and phylogenetic diversity (Miazaki et al. 2015; Zappi et al. 2017; Pontara et al. 2018; Campos et al. 2021). Probably the highest species richness, PD, and lowest MNTD found in the FOR are related to the highest finer soil particle contents (i.e. clay, silt, and fine sand) (Supplementary Material, Table A1). Finer soil particles account for greater water retention and availability (Schaefer et al. 2016), as well as enabling greater physical support for roots (Assis et al. 2011), having a strong influence on the forested vegetation of the rupestrian complex (Negreiros et al. 2014; Ferrari et al. 2016). In addition, our results showed that these metrics were influenced by soil fertility. The greater species richness and PD found in FOR may be related to lower nutrient availability (i.e. $\mathrm{Ca}^{2+}, \mathrm{Mg}^{2+}$, remaining phosphorus, $\mathrm{Mn}, \mathrm{Zn}$, organic matter). The highest values observed in PD and species richness are expected in environments with lower nutrient availability (Huston 1993; Nadeau and Sullivan 2015) since soils with lower fertility normally have reduced interspecific competition (Gastauer and Meira-Neto 2014); this is because efficient competitors may lack resources to outcompete inferior competitors, thereby causing higher tree species number (Tilman 1985).

\section{Conclusions}

1. In an isolated tepui (Tepequém table mountain) of Brazilian Amazonian, plant community composition and key plant diversity dimensions (i.e. taxonomic and phylogenetic) varied considerably along localscale edaphic and topographic gradient. In this tepui, the floristic and phylogenetic compositions were different among the three main phytophysiognomies (Open Rupestrian Grassland, Shrubby Rupestrian Grassland and Forest).

2. Species richness and phylogenetic diversity decrease with increasing altitude.

3. The shrubby vegetation showed negative values for all standardised phylogenetic metrics, indicating phylogenetic clustering at middle altitude, probably due to biotic interactions. At lower altitudes, the forest 
showed a cluster pattern when only terminal nodes (recent) are considered, suggesting the disappearance of some of the rare species from the community.

4. The forest (lowest altitude) and Open Rupestrian Grassland (highest altitude) showed random dispersion to deep (old) phylogenetic nodes. Hence neutral processes may shape the communities, or different deterministic processes act simultaneously to obscure structure patterns in these phytophysiognomies.

5. Altitude, soil texture and fertility affect species richness and different phylogenetic diversity metrics.

6. Comprehensive studies, including the role of environmental drivers in plant evolutionary history along the altitudinal gradient are essential not only for understanding the mechanism involved in mountaintop plant community assemblies, but also to provide additional information for conservation planning of this highly threatened ecosystem worldwide.

\section{Declarations}

\section{Acknowledgements}

The authors thank the Brazilian Coordination for the Improvement of Higher Education Personnel (CAPES) for granting a scholarship to the first author.

\section{Contributions}

PVC, CEGRS, VP and PMV conceived the idea and designed methodology. PVC, MVBX, JFVJ and GRC collected the samples. PVC, VP and PMV analyzed the taxonomic and phylogenetic data. PVC wrote of the manuscript. All authors contributed critically to the drafts and gave final approval for publication.

\section{Conflict of interest}

The authors declare that they have no conflict of interest.

\section{References}

1. Angiosperm Phylogeny Group (2016) An update of the Angiosperm Phylogeny Group classification for the orders and families of flowering plants: APG IV. Bot J Linn Soc 181: 1-20.

2. Almeida-Filho R, Shimabukuro YE (2002) Digital processing of a Landsat-TM time series for mapping and monitoring degraded areas caused by independent gold miners, Roraima State, Brazilian Amazon. Remote Sens Environ 79: 42-50.

3. Amâncio BCS, Govêa KP, Trindade LOR, Neto ARC, Souza TC, Barbosa, S (2019) Sandwich method applied to the screening of allelopathic action in Byrsonima spp. (Malpighiaceae). Biologia 25: 1-8.

4. Barbosa RI, Miranda IS (2004) Fitofisionomias e diversidade vegetal das Savanas se Roraima [Phytophysiognomies and plant diversity of the Roraima savanas]. In: Barbosa RI, Xaud HAM, Costa 
e Souza EM (eds) Savanas de Roraima: Etnoecologia, biodiversidade e potencialidades agrossilvipastoris. FEMACT: Boa Vista, pp 61-78.

5. Benites VM, Caiafa AN, Mendonça ES, Mendonça EdeSá, Schaefer CEGR, Ker JC (2003) Solos e vegetação nos complexos rupestres de altitude da Mantiqueira e do Espinhaço. Floram 10: 76-85.

6. Beserra Neta LC, Júnior SST, da Costa ML (2015) Tepequém Mountains: A Relict Landscape in the Northern Amazon. Lands Landf Braz 24: 262-275.

7. Braun-Blanquet J (1979) Phytosociology. Basis for the study of plant communities. Blume, Madrid.

8. Bray JR, Curtis JT (1957) An ordination of the upland forest communities of southern Wisconsin. Ecol Monogr 27: 325-349.

9. Cadotte MW, Carscadden K, Mirotchnick N (2011) Beyond species: functional diversity and the maintenance of ecological processes and services. J Appl Ecol 48: 1079-1087.

10. Cadotte MW, Tucker CM (2017) Should environmental filtering be abandoned? Trends Ecol Evol 32: 429-437.

11. Campos PV, Schaefer CEGR, Pontara V, Senra EO, Viana PL, Oliveira FS, Candido HG, Villa PM (2021) Exploring the relationship between soil and plant evolutionary diversity in the Roraima table mountain OCBIL, Guayana Highlands. Biol J Linn Soc XX: 1-17.

12. Campos PV, Villa PM, Nunes JA, Schaefer CEGR, Porembski S, Neri AV (2018) Plant diversity and community structure of Brazilian Páramos. J Mt Sci 15: 1186-1198.

13. Cavender-Bares J, Kozak KH, Fine PVA, Kembel SW (2009) The merging of community ecology and phylogenetic biology. Ecol Lett 12: 693-715.

14. Chun JH, Lee CB (2018) Diversity patterns and phylogenetic structure of vascular plants along elevational gradients in a mountain ecosystem, South Korea. J Mt Sci 15(2): 280-295.

15. Cordeiro AAC, Neri AV (2019) Spatial patterns along an elevation gradient in high altitude grasslands, Brazil. Nord J Bot 37 (2): 1-10.

16. Crawley MJ (2013) The R Book, second ed. John Wiley \& Sons, West Sussex, U.K.

17. Dinno A (2017) "dunn.test” package: Dunn's test of multiple comparisons using rank sums. R Studio package version online: http://CRAN.R-project. org/package= dunn.test (Accessed on 7 january 2020).

18. Empresa Brasileira de Pesquisa Agropecuária (EMBRAPA) (2017) Manual de Métodos de Análise de Solo, third ed. Embrapa Solos. Brasília.

19. Faith DP (1992) Conservation evaluation and phylogenetic diversity. Biol Conserv 61: 1-10.

20. Fernandes GW, Almeida HA, Nunes CA, Xavier JHA, Cobb NS,Carneiro MAA, Cornelissen T, Neves FS, Ribeiro SP, Nunes YRF, Pires ACV, Beirão MV (2016) Cerrado to rupestrian grasslands: patterns of species distribution and the forces shaping them along an altitudinal gradient. In: Fernandes GW (eds) Ecology and Conservation of Mountaintop Grasslands in Brazil. Springer International Publishing AG Switzerland, pp 345-371. 
21. Ferrari LT, Schaefer CEGR, Fernandes RBA, Mendonça BAF, Gjorup DF, Corrêa GR, Senra EO (2016) Thermic and Hydric Dynamics of Ironstone (Canga) and Quartzite Rupestrian Grasslands in the Quadrilátero Ferrífero: The Ecological Importance of Water. In: Fernandes GW (eds) Ecology and Conservation of Mountaintop Grasslands in Brazil. Springer International Publishing AG Switzerland, pp 71-85.

22. Fox J, Weisberg S, Adler D (2014) Package "car". R package version 2.1-2, companion to applied regression. http://CRAN.R-proje ct.org/packa ge=car

23. Gastauer M, Meira-Neto JAA (2014) Interactions, Environmental Sorting and Chance: Phylostructure of a Tropical Forest Assembly. Folia Geobot 49: 443-459.

24. Goberna M, García C, Verdú M (2014) A role for biotic filtering in driving phylogenetic clustering in soil bacterial communities. Global Ecol Biogeogr 23: 1346-1355.

25. Hubbell SP (2001) The unified neutral theory of biodiversity and biogeography. Princeton University Press, Oxford.

26. Huber O (1987) Consideraciones sobre el concepto de Pantepui. Pantepui 2: 2-10.

27. Huber O (1995) Geographical and physical features. In: Berry PE, Holst BK, Yatskievych K, (eds) Flora of the Venezuelan Guayana. vol. 1, Introduction. Missouri Botanical Garden Press, Saint Louis, pp 161.

28. Husson F, Josse J, Le S, Mazet J (2017) “FactoMineR" package Multivariate: Exploratory Data Analysis and Data Mining online: http://CRAN.R-project. org/package=FactoMineR (Accessed on 9 january 2020).

29. Huston MA (1993) Local Processes and Regional Patterns: Appropriate Scales for Understanding Variation in the Diversity of Plants and Animals. Oikos 86: 393-401.

30. Jin Y, Qian H (2019) V.PhyloMaker: an R package that can generate very large phylogenies for vascular plants. Ecogeg 42: 1353-1359.

31. Kembel SW, Ackerly DD, Blomberg SP, Cornwell WK, Cowan PD, Helmus MR, Morlon H, Webb CO (2015) Package "picante". R tools for integrating phylogenies and ecology. R package version 1.6-2.

32. Körner C, Jetz W, Paulsen J, Payne D, Rudmann-Maurer K, Spehn EM (2017) A global inventory of mountains for biogeographical applications. Alp Bot 127: 1-15.

33. Le Stradic S, Buisson E, Fernandes GW (2015) Vegetation composition and structure of some neotropical mountain grasslands in Brazil. J Mt Sci 12: 864-877.

34. Li XH, Zhu XX, Niu Y, Sun H (2014) Phylogenetic clustering and overdispersion for alpine plants along elevational gradient in the Hengduan Mountains Region, southwest China. J Syst Evol 52: 280-288.

35. Liu M, Che Y, Jiao J, Li L, Jiang X (2019a) Exploring the community phylogenetic structure along the slope aspect of subalpine meadows in the eastern Qinghai-Tibetan Plateau, China. Ecol Evol 9: $5270-5280$.

36. Liu C, Qiao X, Wang Z, Lu S, Hou M, Wentworth TR, Hou D, Guo K (2019b) Distinct taxonomic and phylogenetic patterns of plant communities on acid and limestone soils in subtropical and tropical 
China. J Veg Sci 31: 194-207.

37. Manish K, Pandit MK (2018) Phylogenetic diversity, structure and diversification patterns of endemic plants along the elevational gradient in the Eastern Himalaya. Plant Ecol Divers 11: 501-513.

38. Mayfield MM, Levine JM (2010) Opposing effects of competitive exclusion on the phylogenetic structure of communities. Ecol Lett 13: 1085-1093.

39. McCain CM, Grytnes JA (2010) Elevational gradients in species richness. eLS 15: 1-10.

40. Miazaki AS, Gastauer M, Meira-Neto JAA (2015) Environmental severity promotes phylogenetic clustering in campo rupestre vegetation. Acta Bot Bras 29: 561-566.

41. Mota GS, Luz GR, Mota NM, Coutinho ES, Veloso MDM, Fernandes GW, Nunes YRF (2018) Changes in species composition, vegetation structure, and life forms along an altitudinal gradient of rupestrian grasslands in southeastern Brazil. Flora 238: 32-42.

42. Mota NM, Rezende VL, Mota GS, Fernandes GW, Nunes YRF (2016) Forces driving the regeneration component of a rupestrian grassland complex along an altitudinal gradient. Braz J Bot 39(3): 845860.

43. Moro MF, Martins FR (2011) Métodos de levantamento do componente arbóreo-arbustivo. In: Felfili JM, Eisenlohr PV, Melo MMRF, Andrade LA, Meira-Neto JAA (eds) Fitossociologia no Brasil: métodos e estudos de casos. Vol. 1. Editora. UFV, Viçosa, pp 174-212.

44. Nadeau MB, Sullivan TP. 2015. Relationships between plant biodiversity and soil fertility in a mature tropical forest, Costa Rica. Inter J For Res 4: 1-13.

45. Nascimento FA, Tavares Júnior SS, Beserra Neta LC (2012) Estudo dos compartimentos geomorfológicos na Serra do Tepequém-RR, através de fotointerpretação em imagens de sensores remotos e produtos integrados via ihs. Rev Geogr 2: 1464-1474.

46. Negreiros D, Le Stradic S, Fernandes GW, Rennó HC (2014) CSR analysis of plant functional types in highly diverse tropical grasslands of harsh environments. Plant Ecol 215: 379-388.

47. Neri AV, Borges GRA, Meira Neto JA, Magnago LFS, Trotter IM, Schaefer CEGR, Porembski S (2017) Soil and altitude drives diversity and functioning of Brazilian Páramos (campo de altitude). J Plant Ecol 10(5): 731-743.

48. Nunes JA, Schaefer CEGR, Ferreira-Junior WG, Neri AV, Corrêa GR, Enrigth NJ (2015) Soil-vegetation relationships on a banded ironstone 'island', Carajás Plateau, Brazilian Eastern Amazonia. An Acad Bras Ciênc 87: 2097-2110.

49. Nóbrega SR, Coelho ALF, Verola CF, Costa IR, Vilaça R, Luz FJF, Araújo WF (2016) Chromosome variations and diversity of Epidendrum ibaguense Lindl. (Orchidaceae) on the Tepequém's Tepuy, Roraima, Brazil. GMR 16: 1-7.

50. Oksanen J, Blanchet FG, Friendly M, Kindt R, Legendre P, McGlinn D, Minchin P R, O'Hara RB, Simpson GL, Solymos P, Stevens H, Wagner HH (2018) Vegan: Community Ecology Package. R package version 2.0-7. 
51. Oliveira ACP, Souza ASPRF, Loiola MIB (2012) Composição florística de uma comunidade savânica no Rio Grande do Norte, Nordeste do Brasil. Acta Bot Bras 26: 559-569.

52. Pashirzad M, Ejtehadi H, Vaezi J, Shefferson RP (2018) Spatial scale-dependent phylogenetic signal in species distributions along geographic and elevation gradients in a mountainous rangeland. Ecol Evol 00: 1-10.

53. Pavoine S (2016) A guide through a family of phylogenetic dissimilarity measures among sites. Oikos 1719-1732.

54. Pavoine S. 2018. Package "adiv"

55. Pontara V, Bueno ML, Rezende VL, de Oliveira-Filho AT, Gastauer M, Meira-Neto JAA (2018) Evolutionary history of campo rupestre: an approach for conservation of woody plant communities. Biodivers Conserv 27: 2877-2896.

56. Porembski S (2007) Tropical inselbergs: habitats types, adaptive strategies and diversity patterns. Rev Bras Bot 30: 579-586.

57. Qian H, Hao Z, Zhang J (2014) Phylogenetic structure and phylogenetic diversity of angiosperm assemblages in forests along an elevational gradient in Changbaishan, China. J Plant Ecol 2: 154165.

58. R Core Team (2020) R: A Language and Environment for Statistical Computing. Vienna, Austria: R Foundation for Statistical Computing, 2014. R Foundation for Statistical Computing.

59. Reis NJ, Carvalho AS (1996) Coberturas sedimentares do Mesoproterozoico do estado Roraima Avaliação e discussão de seu modo de ocorrência. Rev Bras Geogr 26: 217-226.

60. Rezende VL, Pontara V, Bueno ML, van den Berg E, Oliveira-Filho AT (2019) Climate and evolutionary history define the phylogenetic diversity of vegetation types in the central region of South America. Oecologia 192: 191-200.

61. Rull V (2007) The Guayana Highlands: A promised (but threatened) land for ecological and evolutionary science. Biotropica 39: 31-34.

62. Rull V, Montoya E, Nogué S, Safont E, Vegas-Vilarrúbia T (2019) Climatic and ecological history of Pantepui and surrounding areas. In: Rull V, Huber O, Vegas-Vilarrúbia T, Señaris C (eds) Biodiversity Pantepui Pristine "Lost World” Neotropical Guiana Highlands, Barcelona, pp 33-54.

63. Rull V, Vegas-Vilarrúbia T, Safont E (2016) The Lost World's pristinity at risk. Divers Distrib 22: 995999.

64. Safford HD (1999) Brazilian Páramos II. Macro - and mesoclimate of the campos de altitude and affinities with high mountain climates of the tropical Andes and Costa Rica. J Biogeogr 26: 713-737.

65. Safont E, Rull V, Vegas-Vilarrúbia T, Holst BK, Huber O, Nozawa S, Vivas Y, Silva A (2014) Establishing a baseline of plant diversity and endemism on a neotropical mountain summit for future comparative studies assessing upward migration: anapproach from biogeography and nature conservation. Syst Biodivers 12: 292-314. 
66. Safont E, Rull V, Vegas-Vilarrúbia T, Montoya E, Huber O, Holst BK (2016) Late Holocene vegetation and fire dynamics on the summits of the Guayana Highlands: The Uei-tepui palynological record. Palaeogeogr Palaeoclimatol Palaeoecol 455: 33-43.

67. Schaefer CEGR, Corrêa GR, Candido HG, Arruda DM, Nunes JA, Araujo RW, Rodrigues PMS, Filho EIF, Pereira AFS, Brandão PC, Neri AV (2016) The physical environment of rupestrian grasslands (campos rupestres) in Brazil: geological, geomorphological and pedological characteristics, and interplays. In: Fernandes GW (eds) Ecology and Conservation of Mountaintop Grasslands in Brazil. Springer International Publishing AG Switzerland, pp 15-53.

68. Schmitz D, Schaefer CEGR, Putzke J, Francelino MR, Ferrari FR, Corrêa GR, Villa PM (2020) How does the pedoenvironmental gradient shape non-vascular species assemblages and community structures in Maritime Antarctica? Ecol Indic 108: 105726.

69. Silva E L (1997) A Vegetação de Roraima. In: Barbosa RI, Ferreira EJG, Castellón EG, eds. Homem, Ambiente e Ecologia no Estado de Roraima (eds) INPA. Manaus, pp 401-415.

70. Silva WA, Villa PM, Schaefer CEGR, Ferreira-Júnior WG, Campos PV, Fialho IF, Neri AV (2019) Diversity and life forms of a woody herbaceous community on the quartzite rocky complexes in the Brazilian Iron Quadrangle. Rev Biol Trop 67 (3): 357-369.

71. Silveira FAO, Negreiros D, Barbosa NPU, Buisson E, Carmo FF, Carstensen DW, Conceição AA, Cornelissen TG, Echternacht L, Fernandes GW, Garcia QS, Guerra TJ, Jacobi CM, Lemos-Filho JP, Le Stradic S, Morellato LPC, Neves FS, Oliveira RS, Schaefer CE, Viana PL, Lambers H (2016) Ecology and evolution of plant diversity in the endangered campo rupestre: a neglected conservation priority. Plant Soil 403: 129-152.

72. Sobral FL, Cianciaruso MV (2012) Estrutura filogenética e funcional de assembléias: (Re)montando a ecologia de comunidades em diferentes escalas espaciais. J Biosci 28: 617-631.

73. Swenson NG (2014) Functional and phylogenetic ecology in R. Springer, New York.

74. Tilman D (1985) The resource-ratio hypothesis of plant succession. Am Nat 125: 439-464.

75. Vegas-Vilarrúbia T, Nogué S, Rull V (2012) Global warming, habitat shifts and potential refugia for biodiversity conservation in the neotropical Guayana Highlands. Biol Conserv 152: 159-168.

76. Villa PM, Martins SV, Oliveira Neto SN, Rodrigues AC, Martorano LG, Monsanto LD, Cancio NM, Gastauer M (2018) Intensification of shifting cultivation reduces forest resilience in the northern Amazon. Forest Ecol Manag 430: 312-320.

77. Webb CO (2000) Exploring the phylogenetic structure of ecological communities: An example for rain forest trees. Am Nat 156: 145-155.

78. Webb CO, Ackerly DD, McPeek MA, Donoghue MJ (2002) Phylogenies and community ecology. Annu Rev Ecol Evol S 33: 475-505.

79. Webb CO, Ackerly DD, Kembel SW (2008) Phylocom: Software for the analysis of phylogenetic community structure and trait evolution. Bioinformatics 24: 2098-2100.

80. Wiens JJ, Graham CH (2005) Niche conservatism: integrating evolution, ecology, and conservation biology. Annu Rev Ecol Evol S 36: 519-539. 
81. Zappi DC, Moro MF, Meagher TR, Lughadha EN (2017) Plant biodiversity drivers in brazilian campos rupestres: Insights from phylogenetic structure. Front Plant Sci 8: 1-15.

82. Zappi C, Moro MF, Walker B, Meagher T, Viana PL, Mota NFO, Watanabe MTC, Lughadha EM (2019) Plotting a future for Amazonian canga vegetation in a campo rupestre context. PLoS One 14: 1-19.

83. Zhang J, Mayor SJ, He F (2014) Does disturbance regime change community assembly of angiosperm plant communities in the boreal forest? J Plant Ecol 7: 188-201.

\section{Figures}

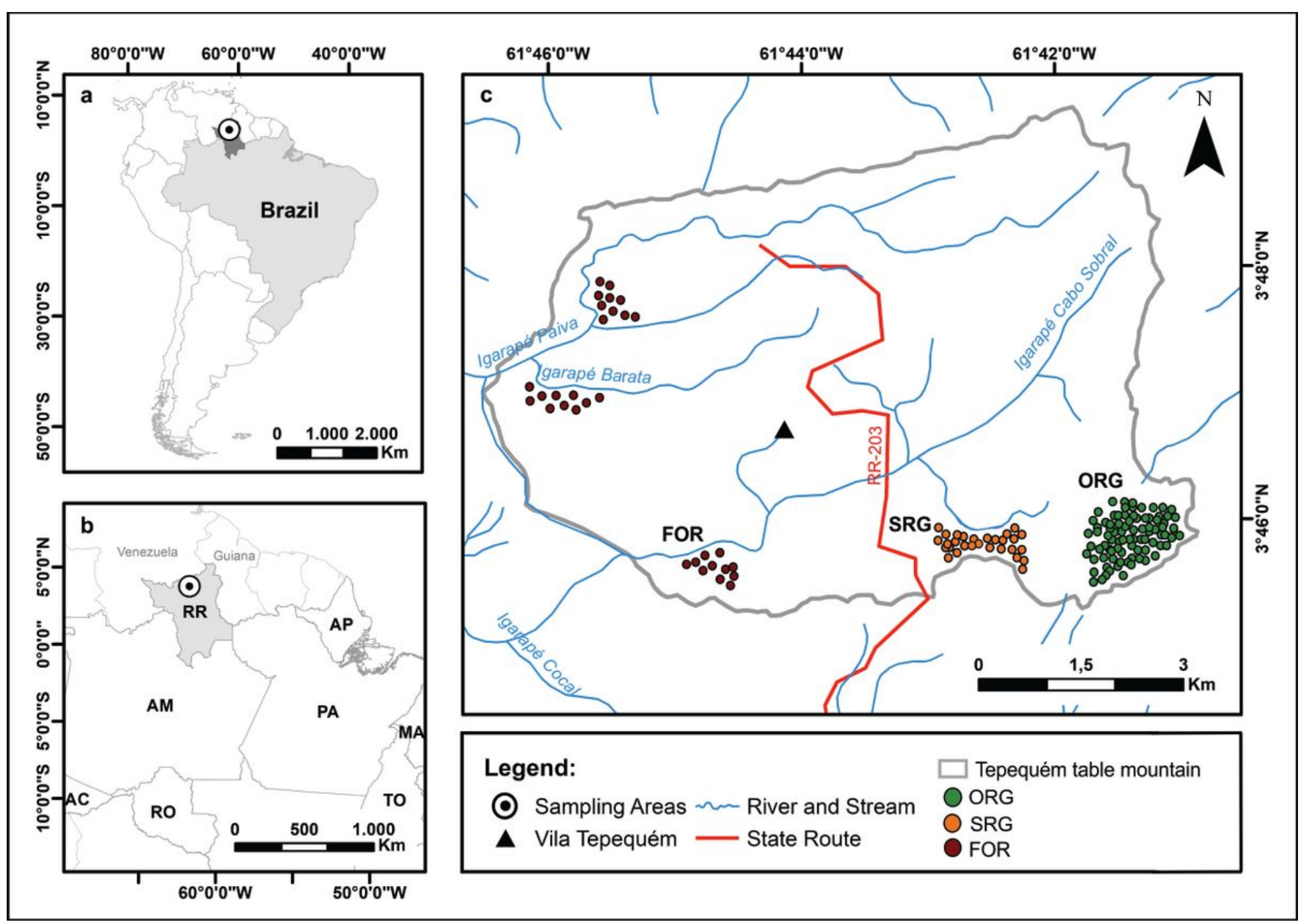

Figure 1

Map of South America (a) with the location of the study area: Roraima state, northwestern Brazil (b); and Tepequém table mountain (c). Vegetation sampling took place at three main Rupestrian Grassland Complex phytophysiognomies: Open Rupestrian Grassland (ORG; green); Shrubby Rupestrian Grassland (SRG; orange); Forest (FOR; red). Note: The designations employed and the presentation of the material on this map do not imply the expression of any opinion whatsoever on the part of Research Square 
concerning the legal status of any country, territory, city or area or of its authorities, or concerning the delimitation of its frontiers or boundaries. This map has been provided by the authors.
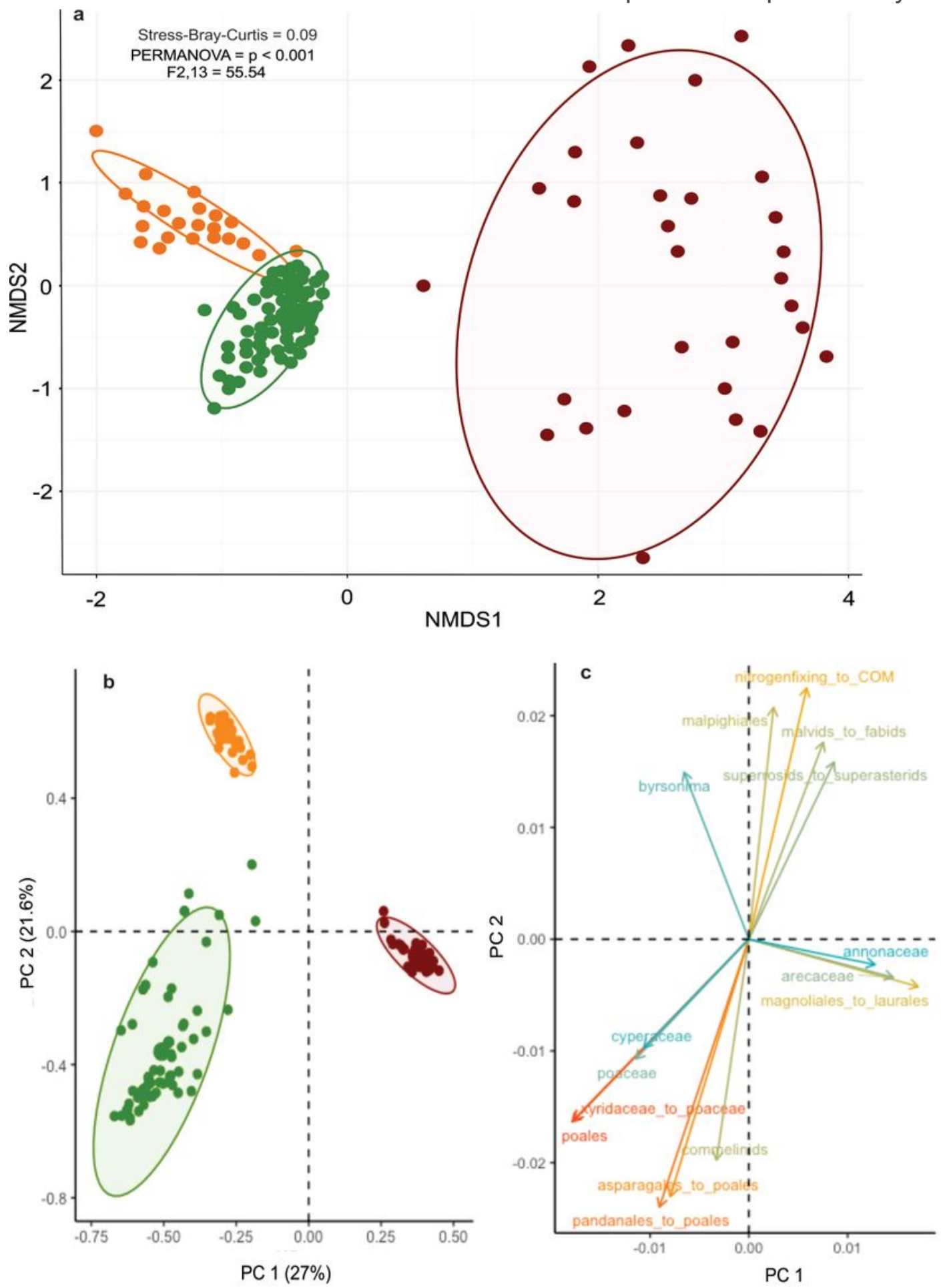

Phytophysiognomy

\begin{tabular}{l}
- ORG \\
\hline
\end{tabular}

Nodes Contribution

Figure 2

Non-metric multidimensional scaling (NMDS) based on species composition (a); and first two axes (PC1 and PC2) from a principal component analysis with Hellinger distance as the coefficient of dissimilarity (evoPCAHellinger) showing the distribution of plots according to their phylogenetic composition (b), and 
the influence of each branch in determining the positions of the plots (c), which were sampled in different phytophysiognomies in the Tepequém table mountain, Roraima state, northwestern Brazil. Lineages are indicated by an arrow (whose direction and size are determined in proportion to the coordinates of the branches). Open Rupestrian Grassland (ORG; green); Shrubby Rupestrian Grassland (SRG; orange); Forest (FOR; red).

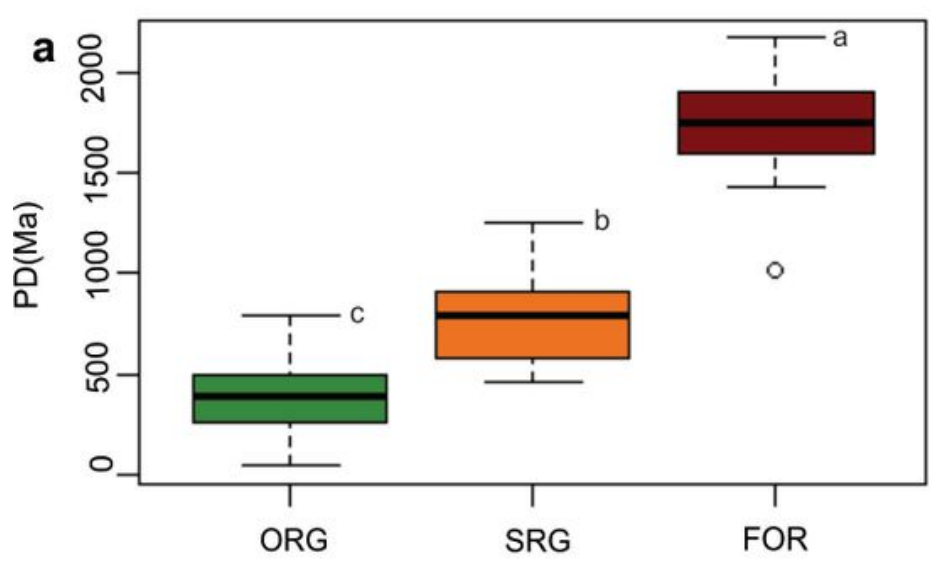

Phytophysiognomy

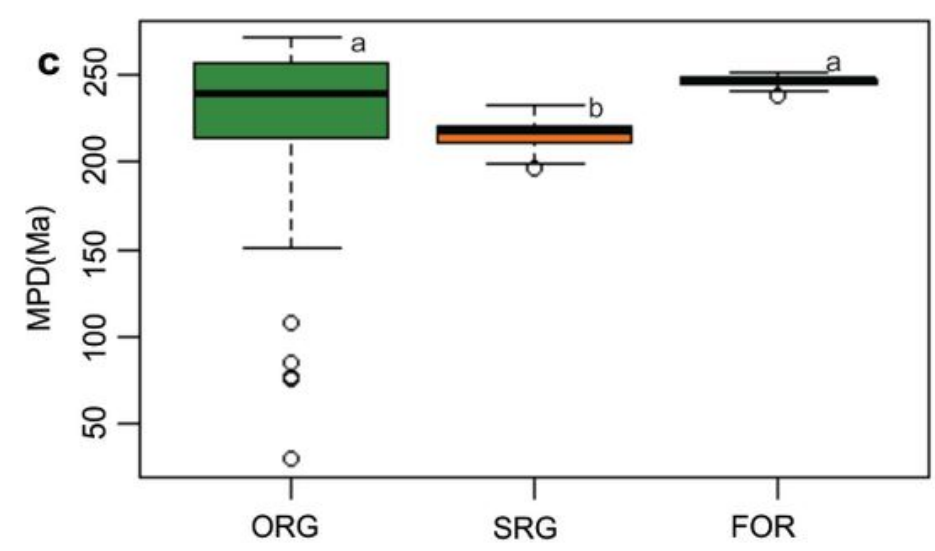

Phytophysiognomy

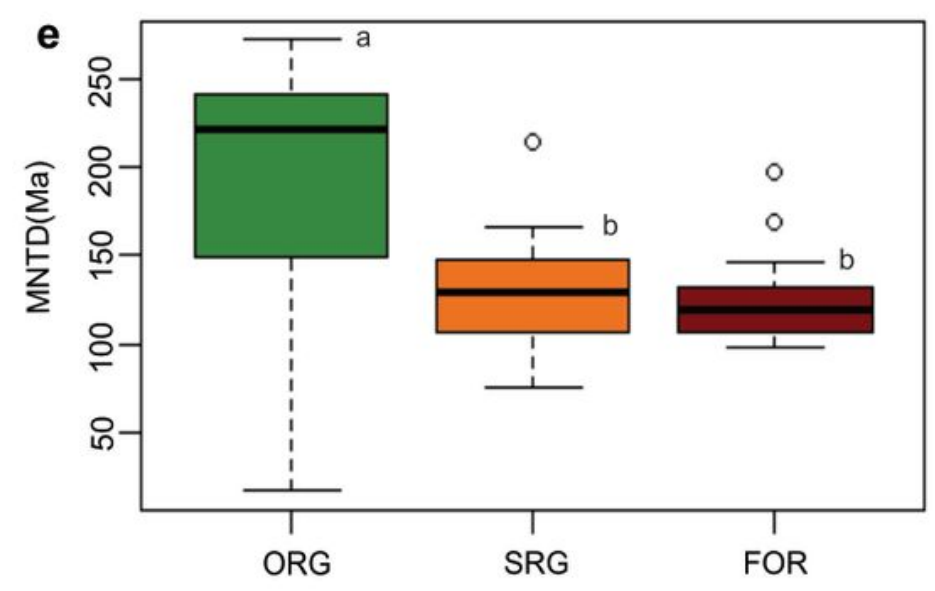

Phytophysiognomy

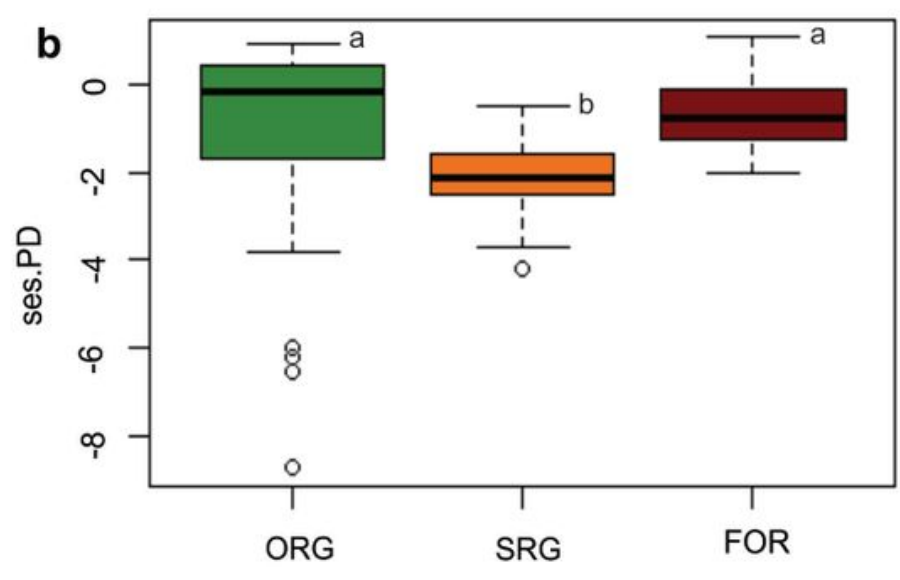

Phytophysiognomy

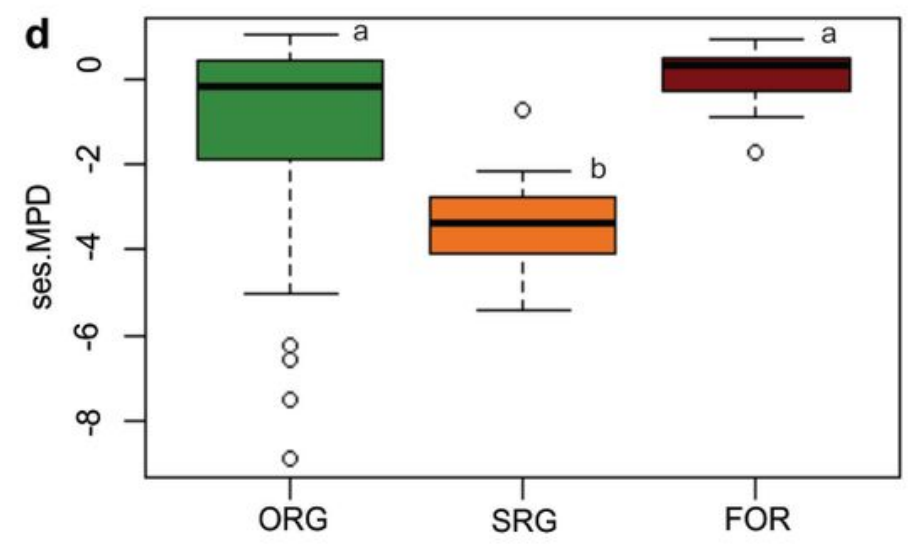

Phytophysiognomy

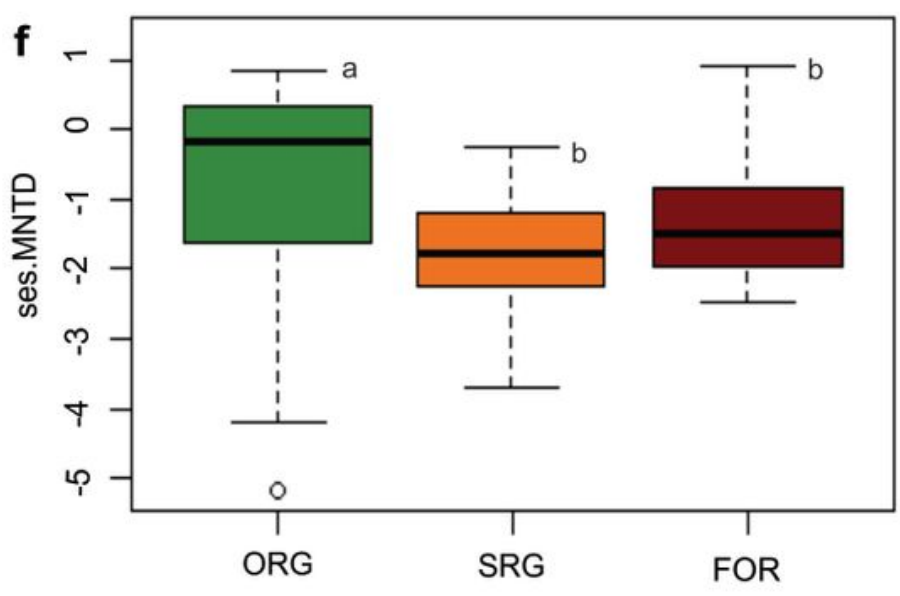

Phytophysiognomy

Figure 3 
Variation in phylogenetic diversity (PD) (a), ses.PD (standard effective size of phylogenetic diversity (b), mean pairwise distance (MPD) (c), ses.MPD (standard effect size of mean pairwise distance among distinct taxa) (d), mean nearest neighbor distance (MNTD) (e), and ses.MNTD (standard effective size of mean nearest taxon distance among distinct taxa) (f) in different phytophysiognomies in the Tepequém table mountain, Roraima state, northwestern Brazil. Different letters indicate significant differences between phytophysiognomies, based in a post hoc Tukey's test $(p<0.05)$. Open Rupestrian Grassland (ORG; green); Shrubby Rupestrian Grassland (SRG; orange); Forest (FOR; red).

a

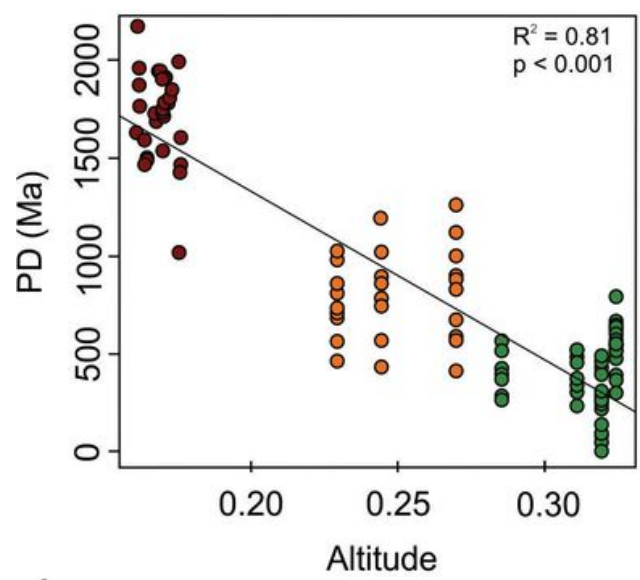

d

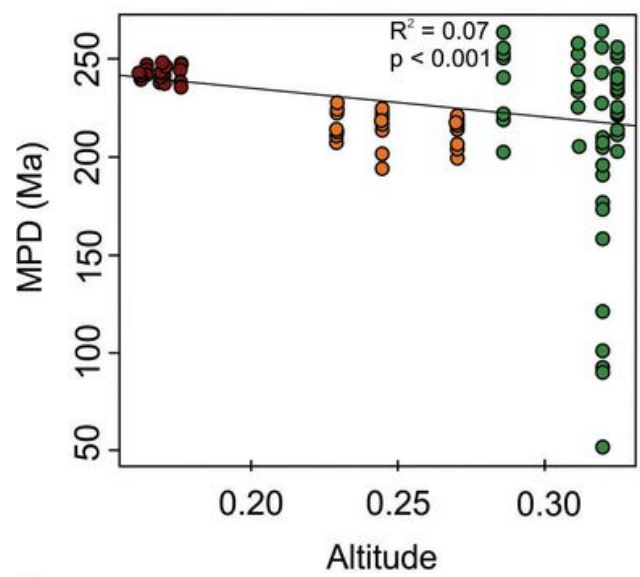

g

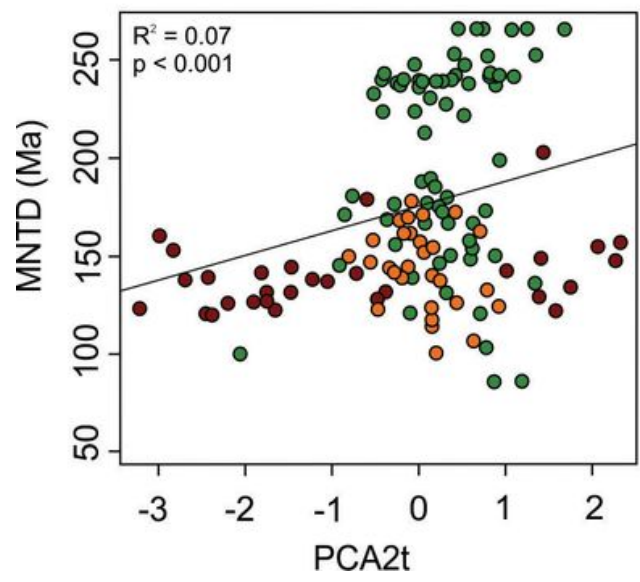

b

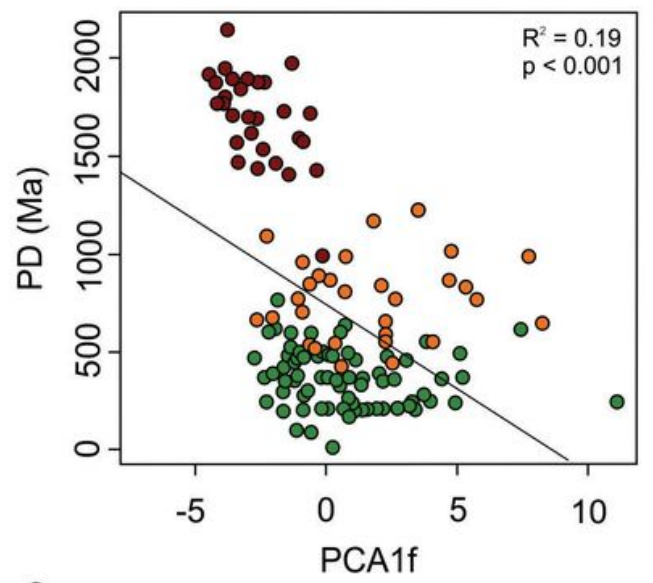

e

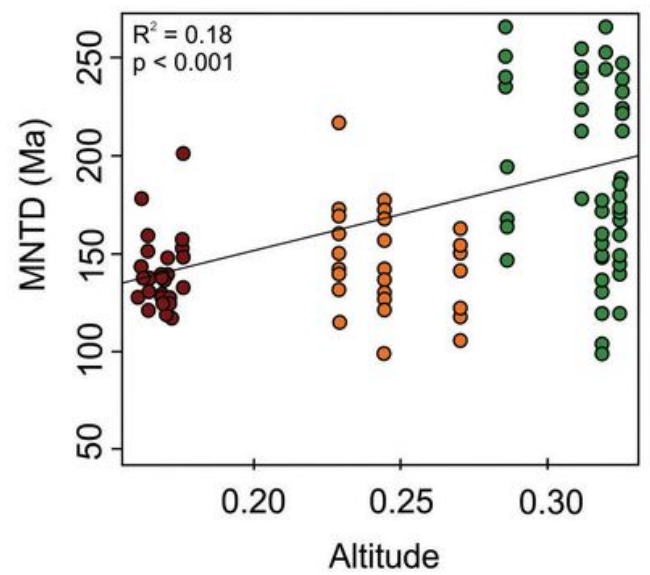

Phytophysiognomy

ORG

SRG

FOR

Figure 4

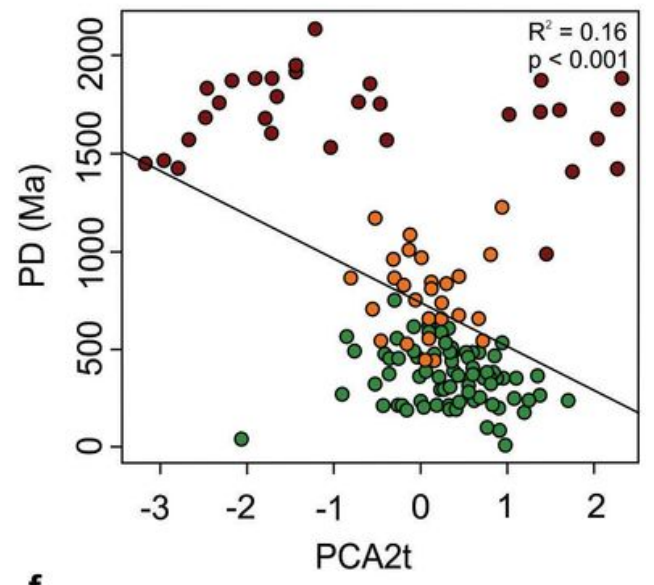

f

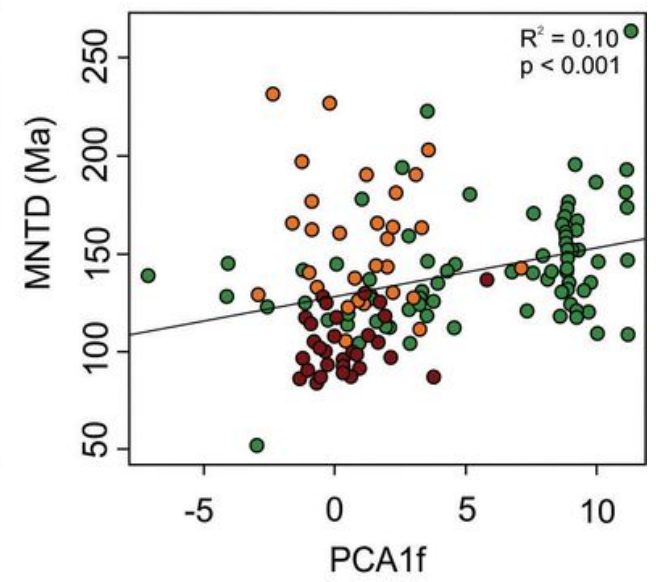


Effects of altitude and soil properties on phylogenetic metrics (a-g) in different phytophysiognomies in the Tepequém table mountain, Roraima state, northwestern Brazil. PD phylogenetic diversity (in myrs) (ac); MPD mean pairwise phylogenetic distance (in myrs) (d); MNTD mean nearest taxon distance (in myrs) (e-g). PCA1 $f$ and PCA2f (variability of nutrients content related soil fertility); and PCA1t and PCA2t (variability of physical properties related soil texture). Open Rupestrian Grassland (ORG; green); Shrubby Rupestrian Grassland (SRG; orange); Forest (FOR; red).

\section{Supplementary Files}

This is a list of supplementary files associated with this preprint. Click to download.

- Supplementarymaterial.docx 